\title{
Neurochemical coding of myenteric neurones in the forestomach of suckling and fattened lambs*
}

\author{
H. Pfannkuche ${ }^{1}$, C. Schellhorn and G. Gäbel \\ Institute of Veterinary-Physiology, Leipzig University \\ An den Tierkliniken 7, D-04103 Leipzig, Germany
}

\begin{abstract}
The distinct functions of reticulum and reticular groove are presumably controlled by neurones of the myenteric plexus. Therefore, we analysed neurones according to their neurochemical code in suckling and fattened lambs. Most neurones in the reticulum were cholinergic, additionally expressing substance $\mathrm{P}$ and presumably excitatory. Nitrergic neurones were more abundant in the reticular groove. In both, reticulum and reticular groove, the proportion of nitrergic neurones increased with age with the increase to be more pronounced in the reticular groove. We conclude that the increase of inhibitory innervation might enable the forestomach to adapt to large amounts of ingesta during rumination.
\end{abstract}

KEY WORDS: forestomach, enteric nervous system, choline acetyltransferase, nitric oxide synthase, substance $\mathrm{P}$, vasoactive intestinal peptide

\section{INTRODUCTION}

Reticulum and reticular groove are forestomach regions which gain importance at different stages of lambs development. Although the motility of both reticular groove and reticulum is controlled by a distinct vagal input, an intrinsic modulation by neurones of the enteric nervous system seems to be also present (Gregory, 1982). Enteric neurones control their target tissues by the release of different combinations of excitatory and inhibitory neurotransmitters. The neurochemical code (= combination of neurotransmitters expressed by a neurone) and the function of enteric neuronal populations are strongly correlated (Brookes, 2001). The study aimed at investigating, which neurochemical codes are expressed by myenteric neurones of reticulum and reticular groove and whether the code changes during development.

\footnotetext{
* Supported by Deutsche Forschungsgemeinschaft, Pf 403/1-1, 403/1-2 and Akademie für Tiergesundheit

${ }^{1}$ Corresponding author: e-mail: pfannku@rz.uni-leipzig.de
} 


\section{MATERIAL AND METHODS}

Specimen (reticulum and floor of the reticular groove) were taken from suckling and fattened lambs. After fixation, whole mount preparations of the myenteric plexus were obtained by dissecting off circular and longitudinal muscle layers. The following antisera were used for staining of myenteric neurones: rabbit anti-choline acetyltranspherase (ChAT), mouse anti-nitric oxide synthase (NOS), rat anti-substance $\mathrm{P}$ (SP), guinea-pig anti-vasoactive intestinal polypeptide (VIP), rabbit anti-neurone-specific enolase (NSE) and mouse anti-HuC/D (Hu). For visualizing the primary antibodies microscopically, fluorophore labelled secondary antibodies were used.

\section{RESULTS}

Myenteric ganglia in the reticulum contained significantly more neurones than myenteric neurones in the reticular groove. Ganglia from suckling lambs were larger in size than ganglia obtained from fattened lamb.

Table 1. Neurochemical code of neurones within reticulum and floor of the reticular groove

\begin{tabular}{lccccc}
\hline & \multicolumn{2}{c}{ Reticulum } & & \multicolumn{2}{c}{ Floor of the reticular groove } \\
\cline { 2 - 3 } \cline { 5 - 6 } Code & $\begin{array}{c}\text { suckling lambs } \\
\mathrm{n}=5\end{array}$ & $\begin{array}{c}\text { fattened lambs } \\
\mathrm{n}=3\end{array}$ & & $\begin{array}{c}\text { suckling lambs } \\
\mathrm{n}=5\end{array}$ & $\begin{array}{c}\text { fattened lambs } \\
\mathrm{n}=3\end{array}$ \\
\cline { 2 - 3 } \cline { 5 - 6 } & \multicolumn{2}{c}{ relative number of neurones, $\%$} & & relative number of neurones, $\%$ \\
\hline $\mathrm{Hu} / \mathrm{ChAT} /-$ & $24 \pm 4^{\mathrm{A}}$ & $21 \pm 5^{\mathrm{A}}$ & & $13 \pm 3^{\mathrm{A}^{*}}$ & - \\
$\mathrm{Hu} / \mathrm{ChAT} / \mathrm{SP}$ & $64 \pm 2^{\mathrm{B}}$ & $62 \pm 3^{\mathrm{B}}$ & & $25 \pm 1^{\mathrm{B}^{*}}$ & - \\
$\mathrm{Hu} / \mathrm{NOS} /-$ & - & - & & $17 \pm 3^{\mathrm{C}^{*}}$ & $3 \pm 5^{\mathrm{A}}$ \\
$\mathrm{NOS} / \mathrm{VIP}$ & $10 \pm 3^{\mathrm{C}^{*}}$ & $17 \pm 4^{\mathrm{A}}$ & & $45 \pm 1^{\mathrm{D}^{*}}$ & $83 \pm 15^{\mathrm{B}}$ \\
$\mathrm{Hu} / \mathrm{VIP} /-$ & - & - & & - & $11 \pm 13^{\mathrm{A}}$ \\
\hline
\end{tabular}

* indicates significant difference between suckling and fattened lambs ONEWAY ANOVA; $\mathrm{P}<0.05$

$\mathrm{A}, \mathrm{B}, \mathrm{C}, \mathrm{D}$ indicate significant differences between the different neurochemical subpopulations within one column ONEWAY ANOVA; $\mathrm{P}<0.05$

In the reticulum of suckling and fattened lambs and the reticular groove of suckling lambs, all myenteric neurones were either immunoreactive for ChAT or for NOS, as could be shown by consecutive staining of ChAT, NOS and the general neuronal marker NSE. In the reticular groove, also neurones were present which were not immunoreactive for ChAT or NOS but only for the general neuronal marker $\mathrm{Hu}$. By quadruple staining against ChAT, NOS, SP and VIP, three and four neurochemical distinct subpopulation could be found in the reticulum and the reticular groove, respectively (Figure 1, Table 1). 


\section{Region- and age-related coding}

Myenteric neurones of the reticulum were primarily cholinergic. Most of them expressed the code ChAT/SP (Table 1). In contrast, most neurones of the reticular groove expressed a nitrergic phenotype.

Comparing the neurochemical code from neurones of suckling and fattened lambs tissue, an age-associated increase in the relative number of nitrergic neurones could be found. This finding was more obvious in the reticular groove than in the reticulum. Additionally, no cholinergic neurones could be obtained in the reticular groove of the fattened lambs (Table 1).
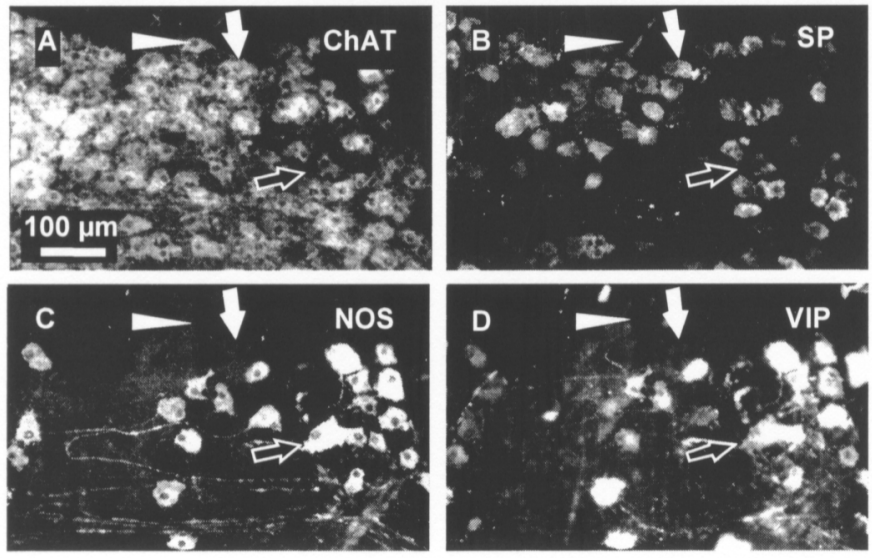

Figure 1. Neurochemical coding in the reticulum. Each photomicrograph shows the same part of one myenteric ganglion. In this ganglion three subpopulations can be differentiated: purely cholinergic neurones (ChAT/-, indicated by an arrowhead), ChAT/SP immunoreactive neurones (white arrow) and NOS/VIP expressing neurones (black arrow)

\section{DISCUSSION}

This study revealed region- and age-specific intrinsic innervation in the reticulum and the reticular groove of suckling and fattened lambs. The prominent cholinergic innervation of the reticulum might point to a pimarily excitatory intrinsic control of this compartment. Acetylcholine as well as SP cause a contraction of the smooth muscle layers in the forestomach (Vassileva et al., 1978; Veenendaal et al., 1982). Retrograde tracing studies have obtained evidence that neurones immunoreactive for ChAT and SP directly take part in the innervation of ruminal smooth muscle layers (Pfannkuche et al., 2002). In our study most neurones that were not immunoreactive for acetylcholine expressed immunoreactivity for NOS and VIP. For this population direct projections to the ruminal muscle has been shown recently. Additionally, NO as well as VIP cause a relaxation when applied onto the forestomach muscles (Denac et al., 1990; 
Barahona et al., 1998). Since we found that neurones immunoreactive for NOS/ VIP neurones are most abundant in the floor of the reticular groove. it might be suggested that the reticular groove is mainly under inhibitory intrinsic control.

When suckling lambs mature to fattened lambs the proportion of nitrergic neurones increased slightly in the reticulum and strongly in the floor of the reticular groove. The complete disapperance of cholinergic neurones during postnatal development seems to be unique in the reticular groove.

\section{CONCLUSIONS}

The excitatory innervation of the reticulum might enable this region to powerful contractions during rumination. The slightly increased inhibitory innervation in the ruminating sheep points also to the ability of this organ to accommodate to large volumes of ingesta. The prominent inhibitory innervation of the floor of the reticular groove could be related to its prominent relaxation during suckling. Since the reticular groove closure hardly appears in adult sheep, the loss of some neuronal populations might hint to a dysfunctional intrinsic innervation in ruminating sheep.

\section{REFERENCES}

Barahona M.V., Sanchez-Fortun S., San Andres M.D., Ballesteros E., Contreras J., San Andres M., 1998. Involvement of the L-arginine/nitric oxide neural pathway in non-adrenergic, noncholinergic relaxation of the bovine oesophageal groove. J. Autonom. Pharmacol. 18, 65-73

Brookes S.J.H., 2001.Classes of enteric nerve cells in the guinea-pig small intestine. Anat. Rec. 262, 58-70

Denac M., Oertle C., Kumin G., Eggenberger E., Scharrer E., 1990. Relaxation of muscle strips from the reticular groove and reticulo-omasal orifice by vasoactive intestinal peptide (VIP). Zbl. Vetmed. A 37, 425-429

Gregory P.C., 1982. Forestomach motility in the chronically vagotomized sheep. J. Physiol. 328, 431-447

Pfannkuche H., Schemann M., Gäbel G., 2002. Ruminal muscle is innervated by non-polarized pathways of cholinergic and nitrergic neurones. Cell Tissue Res. 309, 347-354

Vassileva P., Stoyanov I., Loukanov Y., 1978. Neurotransmitted responses of smooth-muscle strips of complex sheep stomach after electrical field stimulation. Acta Physiol. Pharmacol. Bulg. 4, 11-18

Veenendaal G.H., Woutersen-Van Nijnanten F.M., Van Miert A.S., 1982. Responses of goat ruminal musculature to substance $\mathrm{P}$ in vitro and in vivo. Vet. Res. Commun. 5, 363-367 